\title{
Integrating research tools to support the management of social-ecological systems under climate change
}

\author{
Brian W. Miller ${ }^{1}$ and Jeffrey T. Morisette ${ }^{1,2}$
}

\begin{abstract}
Developing resource management strategies in the face of climate change is complicated by the considerable uncertainty associated with projections of climate and its impacts and by the complex interactions between social and ecological variables. The broad, interconnected nature of this challenge has resulted in calls for analytical frameworks that integrate research tools and can support natural resource management decision making in the face of uncertainty and complex interactions. We respond to this call by first reviewing three methods that have proven useful for climate change research, but whose application and development have been largely isolated: species distribution modeling, scenario planning, and simulation modeling. Species distribution models provide datadriven estimates of the future distributions of species of interest, but they face several limitations and their output alone is not sufficient to guide complex decisions for how best to manage resources given social and economic considerations along with dynamic and uncertain future conditions. Researchers and managers are increasingly exploring potential futures of social-ecological systems through scenario planning, but this process often lacks quantitative response modeling and validation procedures. Simulation models are well placed to provide added rigor to scenario planning because of their ability to reproduce complex system dynamics, but the scenarios and management options explored in simulations are often not developed by stakeholders, and there is not a clear consensus on how to include climate model outputs. We see these strengths and weaknesses as complementarities and offer an analytical framework for integrating these three tools. We then describe the ways in which this framework can help shift climate change research from useful to usable.
\end{abstract}

Key Words: agent-based modeling; complex-adaptive systems; natural resource management; scenario planning; simulations; species distribution modeling; state-and-transition modeling

\section{INTRODUCTION}

Developing strategies for adapting to climate change not only requires regionally and locally relevant climate projections, but also information on the expected impacts of climate change on a range of key social and ecological variables. Crafting management plans is especially challenging because social-ecological systems are complex and adaptive, exhibiting heterogeneity, nonlinearity, interactions across scales, and sensitivity to initial conditions (Malanson et al. 2006, Portugali 2006). These systems also produce aggregate patterns, which emerge from simple interactions between individual components (Holland 1995, Manson 2001, Abel and Stepp 2003). Emergent properties, feedbacks, unanticipated consequences, and thresholds all pose challenges to measuring and predicting system behavior and its responses to potential management actions.

The broad, interconnected nature of these challenges demands that a variety of assessment and planning tools be brought to bear on making decisions for how to manage social-ecological systems under climate change. We followed the suggestion that research should focus on developing analytical frameworks for assessing climate change impacts and their interactions with other stressors (Staudt et al. 2013). We first reviewed three tools, which have been promoted as useful for guiding natural resource management decisions under climate change: species distribution modeling, scenario planning, and simulation modeling. Although each has proven useful, their use and development has been fairly isolated even though there are potentially strong synergies when considered collectively. As a result, we propose a novel analytic framework for integrating these tools and drawing on their complementary strengths to inform natural resource management under climate change. We then discuss how this workflow contributes to the goal of producing 'actionable' climate science (ACCCNS 2013, Asrar et al. 2013) and to the shifting climate information from 'useful to usable' by emphasizing interaction with stakeholders, providing added value to climate data, and offering opportunities for information customization (Lemos et al. 2012).

\section{SPECIES DISTRIBUTION MODELING}

A fundamental aspect of ecology, conservation biology, and resource management is understanding the environmental conditions and geographic areas that are suitable for a given species to inhabit. Species distribution modeling (SDM) is commonly used to determine such areas. In these models, environmental variables are used as the explanatory (independent) variables to estimate the potential habitat (dependent variable) for a given species (Guisan and Zimmermann 2000, Guisan and Thuiller 2005). These models are built on field data consisting of known presence and possible absence locations of a given species as well as the values of environmental or climatic covariates thought to define the species' habitat suitability at these locations. These covariate data are generally extracted from remotely sensed imagery, interpolated/ gridded historical climate data, or downscaled climate model output.

It has been argued that climate is often the most basic determinant of a species fundamental niche in that it limits the species' range at the broadest spatial scale (Araújo and Peterson 2012). Climate

${ }^{1}$ Department of the Interior North Central Climate Science Center, Natural Resource Ecology Laboratory, Colorado State University, ${ }^{2}$ U.S. Geological Survey 
change and SDMs can be connected through the exploration of climate variables, or climate derivatives such as BIOCLIM summaries (Nix 1986), as the explanatory variable. The modeling thus provides a data-driven method to explore the relationship between species occurrence locations and climate based on contemporary, or previous (i.e., historic) information. If the model diagnostics indicate a decent fit and strong predictive capacity, then it is reasonable to apply future climate projections to the relationships from the model to derive corresponding projections of potential habitat. There are significant assumptions and uncertainties in such coupled modeling and projections analysis (Heikkinen et al. 2006, Thuiller 2007), including the uncertainty in both the contemporary and future predictor variables and the models' general inability to fully capture species interactions, migration, dispersal, time lags, or adaptation mechanisms (Sinclair et al. 2010). Given the numerous caveats for SDM, as well as their ability to incorporate and associate significant climate and species location information, it seems prudent to exploit these modeling techniques to the furthest extent possible as a means to develop, as opposed to test, hypotheses regarding how climate can influence current and future species distributions.

So, for the practical application of SDMs to natural resource management decisions under a changing climate, we are left with powerful statistical data-driven models with considerable uncertainties and a long list of caveats. There are numerous papers (only a small sample are referenced above) that describe the limitations and proper use of these models (for a summary, see Araújo and Peterson 2012). At this point, it seems that some of these limitations are inherent to the underlying concept of statistically, data-driven SDMs. That is, even significant advances in statistical, machine learning, or any other techniques will not allow models based on current observations to predict the future state of complex coupled social-ecological-climate conditions.

The appropriate application of these models is largely dependent on placing SDMs within a clear conceptual framework, and thereby identifying their purpose and assumptions (Araújo and Peterson 2012). In fact, SDMs are likely to be more compelling as "part of a methodological toolkit" that addresses the interactions with other dynamics such as climate and land use change (Franklin 2013:1220). In other words, "combining SDM with other data and approaches, such as spatially explicit models of population and community dynamics, may improve forecasting and impact assessment of environmental change at larger spatial scales" (Elith and Franklin 2013:704). Given this conclusion, we propose the integration of SDM with scenario planning and simulation modeling. We go on to provide background information on these topics and propose an analytical framework for such integration.

The proposed workflow builds on previous suggestions for using multiple scenarios of climate change to deal with climate model uncertainty when estimating future species distributions (Araújo and New 2007, Wang et al. 2012, Talbert et al. 2013). Other studies have used SDMs for conservation or restoration prioritization under climate uncertainty (Kujala et al. 2013, Veloz et al. 2013) and to assess alternatives for allocating conservation resources under different emissions scenarios (Carvalho et al. 2011). Although these approaches have made considerable progress toward addressing the uncertainty associated with climate change projections, SDM research typically does not develop future scenarios in conjunction with a variety of stakeholders to account for other dynamics, which might interact with climate changes. In the following sections, we detail how coupling SDMs with the participatory development of place-based, social-ecologicalclimate scenarios, and simulation models could help overcome some of the remaining challenges facing SDM.

\section{SCENARIO PLANNING}

Projected changes in local climates and environments are associated with substantial uncertainty. Moreover, climate change is playing out over large spatial and temporal scales and also interacts with diverse social and biophysical factors, which are not included in SDMs, making it largely uncontrollable in the context of local or regional resource management. Scenario planning is an effective tool for creating management plans under such uncertainty and largely uncontrollable external drivers (Peterson et al. 2003a).

Scenario planning is the process of developing a set of plausible futures for a given system. In this instance, scenarios are not necessarily equivalent to climate scenarios, which capture a set of modeled future situations with different assumptions (i.e., emission scenarios that represent a range of deviations in precipitation or temperature), but are structured accounts of plausible futures, which are developed to better understand current trajectories, drivers of change, and response options (Peterson et al. 2003a). Each scenario is based on a set of assumptions about important relationships and driving forces in a given area or location; different scenarios reflect alternative economic, environmental, social, and technological conditions (Walker et al. 2003). As such, scenario planning can incorporate a variety of data types and perspectives (Peterson et al. 2003a). It is especially useful for incorporating factors that are difficult to model or include in quantitative approaches. For instance, values and agency, which are not readily represented in SDMs, are at the center of scenario development (Kass et al. 2011).

Scenario planning has been applied to a variety of sectors, including energy (Wack 1985), advertising (Schoemaker 1995), governance (Kahane 1998), and natural resource management (Weeks et al. 2011; for a recent review of scenario development for environmental decision making, see Mahmoud et al. 2009). It can also be applied across multiple locations and geographic scales (Rotmans et al. 2000, Foran et al. 2013). Scenario planning has proven to be a useful tool for creating strategies under uncertainty, and it can have the additional benefits of engaging communities in planning (Tompkins et al. 2008) and natural resource management (Dowsley et al. 2013), and it can improve organizational resilience and the adoption of innovations (Cobb and Thompson 2012).

Rose and Star (2013) described the process by which resource managers can develop and apply scenarios to the management of their own systems. The process, adapted from the Global Business Network, entails five phases and associated tasks:

1. Orientation - determine the central challenge, question, goals, and team

2. Exploration - identify key forces, variables, trends, and uncertainties related to the central question 
3. Synthesis - generate three to five plausible, thoughtprovoking, and divergent scenarios

4. Application - create actions and strategies based on
scenarios

5. Monitoring - identify indicators of change for monitoring

The scenario planning process has been used to guide naturalresource management decisions that are faced with substantial uncertainty. For instance, Peterson et al. (2003b) developed three divergent social-ecological scenarios, which described potential futures for the Northern Highlands Lake District of Wisconsin. These scenarios captured key uncertainties in future development and the use of ecological services in the area, and served as a starting point for a participatory discussion of how to plan under these uncertainties. The scenario-development process itself brought together a diverse group of people and provided them with a better understanding of ongoing changes and new tools for environmental management (Peterson 2007).

Through this process, which generally consists of a series of workshops, scenario planning helps participants overcome biases, identify uncertainties, and distill a variety of information into a manageable number of possible states (Schoemaker 1995). In this way, it can aid in the identification of otherwise unexpected futures, but it is bounded by our capacity to integrate information. In other words, the development of scenarios can still be influenced by participant biases (Schoemaker 1995).

\section{SIMULATION MODELING}

Although scenario planning is an effective tool for describing possible system future states in the face of substantial uncertainty, it is less well suited for predicting complex dynamics (e.g., thresholds, interactions, emergent patterns), the secondary effects of natural resource management, or climate change mitigation plans. Social-ecological systems are complex, adaptive, and are characterized by diverse and independent components, interaction between components, nonlinearities, and selection processes, which all produce variation and novelty (Levin 1998). As a result, it is unreasonable to assume that we are able to predict overall system behavior based on understandings of individual system components (Walker and Salt 2006). Moreover, system thresholds can only be detected by crossing them, a relatively rare and unexpected occurrence, which is potentially unpredictable, extreme, and an irreversible form of experimentation on large, complex systems (Carpenter 2003, cited in Carpenter et al. 2005). However, the identification of thresholds is necessary for preventing sudden undesirable changes.

Computer-based simulation models have been advocated as ways of reproducing complex dynamics and implementing 'what if' scenarios (Axelrod 1997, Erlien et al. 2006) and are also promising means of identifying thresholds. We reviewed two simulation tools, which have been increasing in use and diversity, and that we see as key to addressing the challenge of managing socialecological systems under climate change: agent-based models and state-and-transition simulation models. In addition, we provide suggestions for how to combine these simulation tools with one another and with SDM and scenario planning; although simulation models can be effectively used to explore management and climate scenarios, they are not appropriate for developing the scenarios themselves (Peterson et al. 2003a).

\section{State-and-transition models}

State-and-transition models originated as conceptual models of rangeland vegetation, which represented groups of vegetation communities and the shifts between them (Westoby et al. 1989). This was proposed as an alternative to the dominant equilibriumbased view of rangelands, wherein succession proceeded steadily toward a climax community. In state-and-transition models, states can either be defined broadly as "...climate/soil/vegetation domains that encompass a large amount of variation in species composition," or more narrowly, "as serial stages or phases of vegetation development" (Stringham et al. 2001:2). Generally, states are suites of vegetation communities, which have distinct functional groups and ecosystem processes, as well as associated vegetation structure and management requirements (Bestelmeyer et al. 2003). Transitions can result from natural events, management interventions, or a combination of both (Stringham et al. 2001), and can be reversible or unidirectional. Conceptual state-and-transition models are typically represented using box and arrow diagrams, in which boxes or nested boxes represent vegetation states, and arrows represent the transitions within and between them.

More recently, there has been a movement toward quantitative computer-based state-and-transition models. These state-andtransition simulation models (STSMs) are based upon conceptual models of vegetation types and their shifts between different possible states. In STSMs, transitions can be deterministic or probabilistic. Deterministic transitions are those that take place after a given period of time, such as aging and growth. Probabilistic transitions occur with a given probability and include processes such as fire, invasion, and restoration.

Spatially explicit STSMs can provide considerable benefit to quantitative simulations. These are analogous to joint cellular automata-Markov models (Parker et al. 2003), hybrid Markovcellular automaton models ( $\mathrm{Li}$ and Reynolds 1997), and spatiotemporal Markov chains (Balzter et al. 1998). As described by Bestelmeyer et al. (2011), spatially explicit STSMs are useful because spatial dynamics such as contagion, feedbacks between patches, spatial patterns in historical legacies, and variation in soils, topography, and climate can all affect the likelihood and location of transitions. In terms of practical implications, accounting for spatial patterns and processes can improve inventory and monitoring by identifying early-warning indicators and sites that are more susceptible to transitions (Bestelmeyer et al. 2011).

Overall, STSMs have proven useful for comparing and evaluating different resource management scenarios (Forbis et al. 2006, Provencher et al. 2007, Frid and Wilmshurst 2009, Strand et al. 2009, Costanza et al. 2012). They can also incorporate climate effects on vegetation (Keane et al. 2008, Strand et al. 2009, Halofsky et al. 2013), but STSMs that include dynamic climate inputs, which directly affect vegetation, have not yet been developed. Finally, although STSMs can be used to engage resource managers and experts (Forbis et al. 2006), there is still a need to clarify and standardize STSM terminology, development, and validation to improve participatory modeling (Knapp et al. 2011). 


\section{Agent-based models}

Agent-based models (ABMs) are another type of computer-based simulation that have seen increased application in resource management research. Agent-based models are composed of three interacting components: an environment, agents, and rules. The environment can range from a simple grid to a detailed landscape, which reflects real-world patterns and processes. Agents are autonomous units, such as animals, livestock, or people, which interact with one another and the environment through a set of user-defined rules. One of the fundamental benefits of ABMs is that they can incorporate individual-level variation, which more accurately reflects heterogeneity in humanenvironment interactions (DeAngelis and Mooij 2005). Agentbased models can not only include detail and variation in resource-use decision making, but can also incorporate uncertainty in particular variables or processes (e.g., climate and population projections).

Agent-based models have been promoted as tools for studying properties of complex-adaptive systems, such as feedbacks and emergence (Berry et al. 2002; see the special issue in PNAS). Recent studies suggest that ABMs are also useful for assessing resilience (Schlüter and Pahl-Wostl 2007, Schlüter et al. 2009, Schouten et al. 2013). These models range from basic and abstracted simulations, which can be used to explore the simple rules that underpin complex patterns (Schelling 1971, Epstein and Axtell 1996), to complicated and highly parameterized simulations of particular places and populations (Walsh et al. 2013). Agent-based models have been applied in many fields and are particularly useful for the exploration of policy and management options (Boone et al. 2002, 2006, Walsh et al. 2006, 2013, Anselme et al. 2010, Miller et al. 2010).

Like STSMs, there have been some initial applications of ABMs to climate change research. In terms of adaptation to climate change, "adaptive capacity can be thought of as an emergent property, one for which ABM is a suitable analytic tool" (Patt and Siebenhüner 2005:317). Agent-based models have been used to explore a range of topics, such as the relationships between climate change and local institutions (Wang et al. 2013), adaptive decision making (Janssen and de Vries 1998, Ziervogel et al. 2005, Aurbacher et al. 2013), migration (Smith et al. 2008, Kniveton et al. 2011, Hassani-Mahmooei and Parris 2012), and land use (Yan et al. 2013, Zhang et al. 2013). However, there is not yet a clear strategy for incorporating climate data into ABMs as a dynamic input. Although agent-based modeling of climate change issues is still in its infancy, it is a promising area of research, especially because ABMs are useful for spatially investigating adaptive capacity and possible system futures, including possible climate futures (Patt and Siebenhüner 2005).

\section{Simulation challenges and opportunities}

Simulation models have been applied to a variety of systems and questions, but they face important challenges related to model specification and validation. First, modelers must balance model abstraction and specification. Highly parameterized models can be useful for evaluating policy recommendations for particular locations and populations, whereas abstract models can yield more generalized information about system dynamics that underlie complex patterns. Stylized models seek to strike a compromise in complicatedness and are useful for exploring scenarios, refining conceptualizations of complex systems, and uncovering data gaps (Miller et al. 2010).

Validation is another major challenge across computer-based simulations (Cooley and Solano 2011). Highly specified models can be validated by comparing model output to aggregate statistics, and individual agent behavior to observed behaviors in a comparable population (Bruch and Atwell 2013; for a summary of empirical validation approaches, see Berk 2008). On the other hand, abstract models can be compared to observed patterns (Grimm et al. 2005) or to hypothesized empirical relationships, which are based on observed mechanisms (Bruch and Atwell 2013). The time period over which simulation models are run is also relevant to validation procedures. Simulation models oftentimes initialize at present and move forward in time to simulate future conditions and dynamics. It is more appropriate to run the model over a historical time period, compare model output to historical and current observations, and then project the model forward into the future. However, model validation can be limited by data availability. In the absence of data for validation, an alternative strategy is to compare model outputs to information from the literature (Evers et al. 2013) or to more widely applied and tested models (Yan et al. 2013).

Despite the shared challenges of model specification and validation, integrating ABMs and STSMs is a plausible and potentially valuable prospect. State-and-transition simulation models are adept at representing spatially explicit ecological dynamics and incorporating thresholds, which are key aspects of complex-adaptive systems. Agent-based models are especially useful for representing agent decision making, albeit in a simplified form, and accounting for variability and uncertainty. The common use of cellular automata (i.e., a grid of cells that each exists in a defined state, which can change based on transition rules and each cell's neighborhood conditions; Parker et al. 2003) to represent dynamic environments in ABMs and STSMs suggests that it is possible to combine them through a common modeling platform. Some researchers have started moving in this direction; Millington et al. created an agent-based model (2008) and a stateand transition model (2009) with the goal of combining these approaches. Both ABMs and STSMs are being applied to climate change issues, but the incorporation of climate data requires further refinement. And although ABMs and STSMs have been proven useful for experimentation and scenario testing, both simulation methods could be improved through more transparent and participatory scenario development.

Linking scenarios with simulations faces several challenges. First, simulations can either be used as a basis for comparison with scenarios that are developed independently by stakeholders, or simulations can be codeveloped through participatory modeling. In both cases, using simulations to explore future scenarios often yields findings that contrast with expectations; it can be difficult to determine if these surprises are caused by unanticipated complex system dynamics or are artifacts of model specification that do not reflect real-world processes. Second, participatory modeling approaches can be problematic because of limitations associated with time, cost, bias, and validation (Matthews et al. 2007). However, participatory modeling is a growing area of research, which can take many forms (Voinov and Bousquet 2010), and is especially promising given the advent of more 
Table 1. Summary of three tools for assisting climate change planning.

\begin{tabular}{|c|c|c|c|c|}
\hline & Key Citations & Strengths & Weaknesses & Relation to Other Methods \\
\hline Species & Guisan and Zimmermann & Developing empirical & Simplifying assumptions & Estimate projected distributions of \\
\hline Distribution & 2000, Guisan and Thuiller & relationships between & regarding species interactions & key species or resources (identified \\
\hline Modeling & $\begin{array}{l}\text { 2005, Araújo and } \\
\text { Peterson 2012, Elith and } \\
\text { Franklin 2013, Franklin } \\
2013\end{array}$ & $\begin{array}{l}\text { biophysical variables and } \\
\text { species ranges; spatially } \\
\text { explicit; statistically rigorous; } \\
\text { data driven }\end{array}$ & $\begin{array}{l}\text { and behaviors; uncertainty in } \\
\text { predictor variables; accounting } \\
\text { for social dynamics }\end{array}$ & $\begin{array}{l}\text { through scenario planning) under } \\
\text { climate change; create input data for } \\
\text { simulation models }\end{array}$ \\
\hline $\begin{array}{l}\text { Scenario } \\
\text { Planning }\end{array}$ & $\begin{array}{l}\text { Peterson et al. 2003, } \\
\text { Mahmoud et al. 2009, } \\
\text { Cobb and Thompson } \\
\text { 2012, Rose and Star } 2013\end{array}$ & $\begin{array}{l}\text { Engaging stakeholders; } \\
\text { planning under uncertainty } \\
\text { and uncontrollability; } \\
\text { challenging conventional } \\
\text { thinking; assessing multiple } \\
\text { aspects of social-ecological } \\
\text { systems }\end{array}$ & $\begin{array}{l}\text { Scenario validation; } \\
\text { accounting for complex } \\
\text { dynamics (thresholds, } \\
\text { emergence, feedbacks); } \\
\text { generating quantified } \\
\text { estimates of outcome variables }\end{array}$ & $\begin{array}{l}\text { Specify focal challenge and question } \\
\text { to be addressed through quantitative } \\
\text { methods; identify key social and } \\
\text { ecological variables; create descriptive } \\
\text { scenarios to inform simulation } \\
\text { development }\end{array}$ \\
\hline $\begin{array}{l}\text { Simulation } \\
\text { Modeling }\end{array}$ & $\begin{array}{l}\text { Epstein and Axtell 1996, } \\
\text { Axelrod 1997, Berry et al. } \\
\text { 2002, Bestelmeyer et al. } \\
\text { 2003, 2011, Parker et al. } \\
2003\end{array}$ & $\begin{array}{l}\text { Capturing complex system } \\
\text { dynamics; exploring "what } \\
\text { if" scenarios; identifying } \\
\text { data gaps }\end{array}$ & $\begin{array}{l}\text { Developing scenarios; } \\
\text { identifying empirical } \\
\text { relationships between species } \\
\text { and biophysical conditions }\end{array}$ & $\begin{array}{l}\text { Validate scenarios (check for internal } \\
\text { consistency); identify unexpected } \\
\text { outcomes; test possible management } \\
\text { strategies }\end{array}$ \\
\hline
\end{tabular}

accessible software platforms (e.g., NetLogo, ST-Sim). A number of studies have already demonstrated the feasibility and utility of integrating various forms of participatory scenario development with simulation modeling (Gurung et al. 2006, Bousquet et al. 2007, Smajgl 2010, Flaxman and Vargas-Moreno 2011, VargasMoreno and Flaxman 2012, Smajgl and Ward 2013).

\section{INTEGRATION}

Currently there is a fairly long, and sometimes disconnected, chain between climate modeling output, analysis of ecological responses to climate forcings, and management options related to those ecological implications. Species distribution models are useful for providing hypotheses of the future distributions of species and resources of interest, but this information alone is not sufficient to guide decisions for how best to manage resources under dynamic and uncertain future conditions, in which these conditions will depend on much more than the predictor layers included in the SDM. Researchers and managers are increasingly collaborating through scenario planning to explore potential futures. Although scenario-planning exercises are often conducted in conjunction with a range of stakeholders in such a way as to encourage broad, creative thinking, they often lack rigorous, data-driven ecological response modeling. Scenarios currently reflect more of a thought exercise, albeit a very useful and productive one, than a repeatable analytical approach combining climate science, ecological response modeling, and management options. As a result, scenarios are rarely thoroughly validated or tested for unexpected outcomes. Simulation models can add quantitative rigor to the exploration of scenarios by accounting for complex system dynamics. However, to date, simulated management options may or may not have been specified by the managers themselves, and there is a lack of clear empirical relationships between climate model output and uncertainty, and related ecosystem responses.

We see these strengths and weaknesses as opportunities for integrating the three tools, particularly in the context of climate change planning (Table 1). Our suggestion that these three tools are complementary is consistent with the idea that 'scenarios need ecologists' and 'ecologists need scenarios' (Bennett et al. 2003). Researchers have described the benefits of scenario planning to particular modeling approaches and the general utility of quantitative approaches (Westhoek et al. 2006, Rinaudo et al. 2013), but have not demonstrated how simulation models can contribute to the scenario planning process, and ultimately, to resource management. So although there have been calls for combining scenario planning with quantitative methods, there is not a clear consensus on how to do so (Kemp-Benedict 2004). We propose a more specific analytical framework for integrating SDM, scenario planning, and simulation modeling in a way that is mutually beneficial and could better serve resource managers dealing with climate change (Fig. 1). It is important to note that this is not a management framework (e.g., adaptive management, conservation planning) or a conceptual framework for understanding broader concepts (e.g., social-ecological systems, vulnerability). The ultimate outcomes of applying the proposed analytical framework, or workflow, would be a set of coupled and repeatable qualitative and quantitative scenarios of expected social-ecological responses to climate change, and spatially explicit implications for implementing adaptation actions.

We recognize that climate and social science are terms that encompass large and diverse bodies of research. We have discussed them very little to limit the scope of the literature review, but we describe their important role in our framework and in climate change planning below. In fact, all of the boxes in Figure 1 are simplifications of complex methodologies; nested within each box is a set of data collection and processing efforts. For example, SDM is a multistep process, which draws on a variety of input data, involves a series of pre- and post-processing steps, and often includes a set of modeling options and outputs, rather than a single model and output (Morisette et al. 2013).

Climate science provides key inputs for multiple methods within this framework (Fig. 1, arrows A, B, C). These data inputs include historical, hindcasted, and projected gridded climate data, as well as summaries of projected climate futures. Gridded climate data 
Fig. 1. Analytical framework for integrating species distribution modeling, scenario planning, and simulation modeling (STSM: state-and-transition simulation modeling, ABM: agent-based modeling) for climate change planning. Key inputs and outputs: (A) summaries of possible climate futures; (B) gridded climate data; (C) historical climate trends and climate projections; (D) critical forces, variables, and impacts; (E) projected distributions of key species or resources; $(F)$ resource-use decision processes and expected human responses to climate change; $(\mathrm{G})$ descriptive social-ecological-climate scenarios and potential management strategies; $(\mathrm{H})$ validated scenarios and outcomes of simulated management strategies. Scenario planning phases were adapted from Rose and Star (2013).

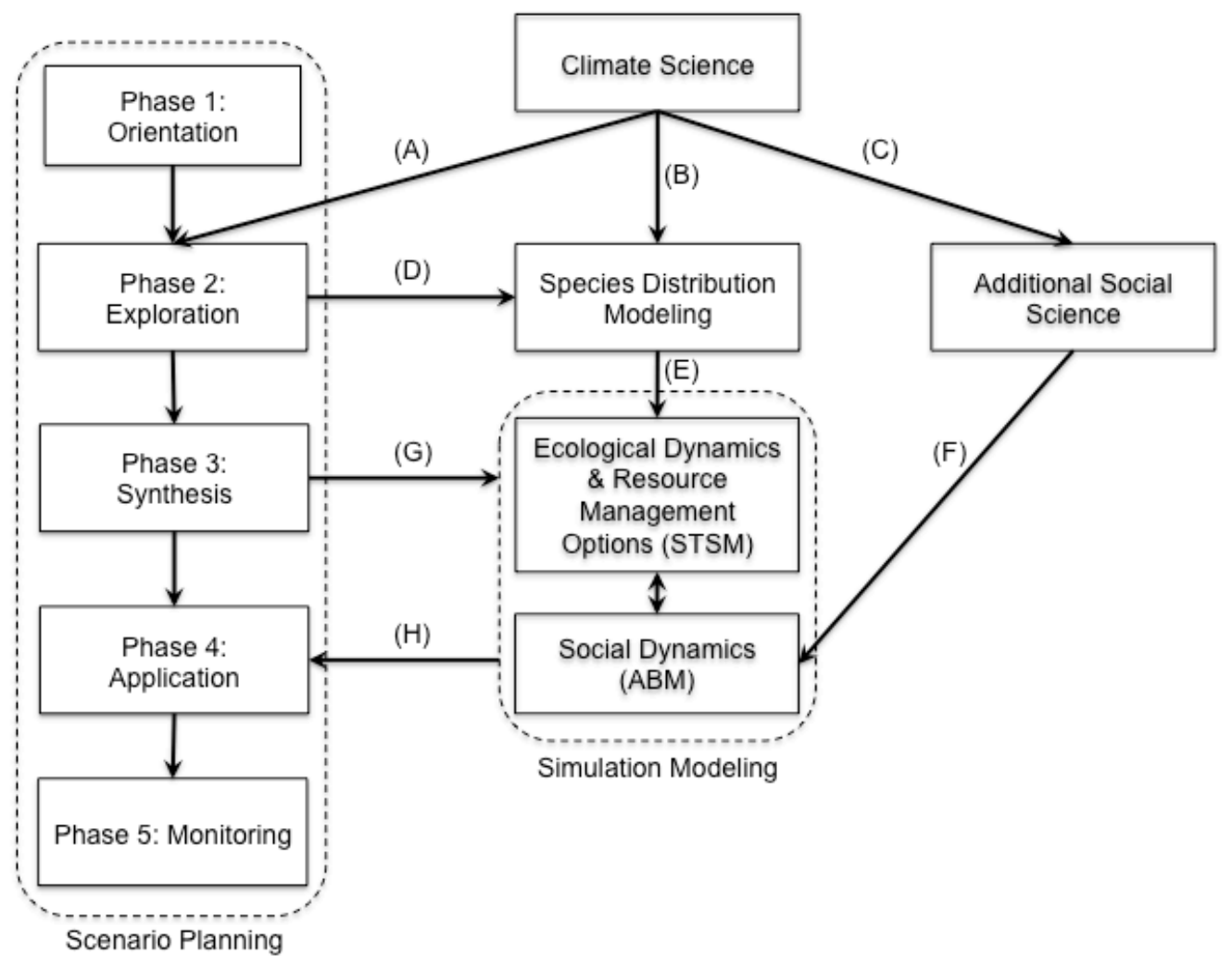

are needed to parameterize SDMs, and climate projections are needed to inform social science on climate exposure and adaptation. Often, these data must be summarized to match the temporal and spatial resolution of the species, system, or process of interest. There are many uncertainties and a growing number of options pertaining to climate data. Selecting appropriate climate scenarios (i.e., climate models, emissions scenarios, and ensemble members), depends upon local climate drivers, data sources, and the target of interest (Snover et al. 2013). As a result, clear communication and partnerships between social and environmental scientists, stakeholders, and the climate science community are needed to ensure that data products are selected, applied, and interpreted appropriately.

As others have pointed out, the process of combining participatory scenario development with quantitative methods can be enhanced by identifying a specific problem and narrowing the topic to be modeled at the outset (Walz et al. 2007). The first phase of the scenario planning process, described by Rose and
Star (2013), addresses this need by emphasizing the identification of a strategic challenge and focal question. During the second phase, scenario building can explore the interactions between biophysical impacts of climate change and social dynamics, and thereby identify key social and environmental metrics associated with various plausible futures (Cumming et al. 2005). This information can be used to direct SDM development (arrow D) and parameterize simulation models (arrow G).

Computer-based simulations add value to scenario planning exercises by providing quantitative and spatially explicit scenario validation (arrow $\mathrm{H}$ ). Simulating social-ecological dynamics would allow for the identification of surprising dynamics associated with the scenarios and for the verification of internal consistency of each scenario, thereby refining conceptualizations of system function. These simulation models could then be used as tools for 'wind tunneling' scenarios; that is, formalizing scenarios and testing policies, actions, or strategies (Rose and Star 2013). 
In particular, STSMs could operationalize the biophysical impacts of climate change and offer a dynamic and spatially explicit environment upon which simulated agents (e.g., wildlife, livestock, and people) operate. The potential biophysical impacts of climate change can be estimated through SDMs, which are the best available tools for translating historical and current data on the factors influencing species distributions into projections of future species ranges under climate change. The outputs of SDMs can serve as key inputs for STSMs (arrow E), which can represent species dynamics under both future climate change and resource management conditions. Researchers could then add agent interactions to the simulation if such interactions were relevant to the scenarios developed through the scenario planning process.

Including social dynamics in such simulations would require an understanding of human decision-making processes, including knowledge of local constraints and opportunities, to accurately characterize individual variation. Scenario planning could identify the key agents and institutions, and additional social science could identify and describe the 'rules' governing their interactions with each other and the environment (e.g., decisionmaking processes, institutional context, opportunities and constraints; arrow F). For instance, ethnographic decision modeling could be used to identify the indicators and processes that resource users or managers use to make decisions about the timing and types of responses to climatic and environmental changes (Miller et al. 2014), which would allow researchers to more accurately simulate the timing and application of potential management responses. This workflow could also draw on socioeconomic models, which range from deterministic statistical models to more qualitative approaches.

Stylized ABMs, coupled with STSMs, would be especially applicable to the simulation of scenarios because they strike a compromise between highly abstract and highly parameterized ABMs. Scenarios inherently contain a substantial amount of uncertainty, and it would be difficult to create a highly specified and fully parameterized ABM from limited quantified information. An added benefit of stylized models is that they do not require the substantial inputs of time, money, and expertise, which are required of highly parameterized models (Miller et al. 2010). Moreover, stylized ABMs are more accessible to nonspecialists and provide visual results, which allow for discussions between multiple stakeholders (Erlien et al. 2006). Participatory modeling is a promising area of research (Parker et al. 2003) and could occur in conjunction with the scenario development process.

Overall, the objective of integrating these tools is not simply to generate model calculations based on scenarios and obtain numerical estimates of scenario outcomes (Döll 2004), but to validate scenarios and test management options under these scenarios. It is worth emphasizing that although simulations can be used to test scenarios and management options, simulation models are not appropriate for developing the scenarios themselves (Peterson et al. 2003a). The role of these simulations in scenario planning would be akin to decision support systems, wherein quantitative models can provide added value to reveal inconsistencies and provide spatial visualizations of the processes described during scenario building (Kok and van Delden 2009). Ultimately, this combination of methods is expected to yield creative yet rigorous scenarios of expected social-ecological responses to climate change, as well as a set of strategies for adapting to these changes. In particular, following this analytical framework would produce a set of validated system futures, management options that have been tested against those futures, as well as monitoring strategies that are tailored to those scenarios.

We are not aware of any studies or organizations that have integrated all of these methods in a systematic way to address issues of climate change adaptation, so we offer an example that draws on multiple studies of the same species (buffelgrass, Pennisetum ciliare) to briefly illustrate the approach. In 2011, 17 researchers convened to explore scenarios of wildfires in Australia (Cary et al. 2012). These participants identified climate change, invasive species including buffelgrass and land use changes as factors that would have substantial bearing on future fire frequency and intensity in their area. The interactions of these factors and possible management responses could have been examined through a combination of species distribution and simulation modeling, similar to that done by Frid et al. (2013), wherein habitat suitability maps were developed as inputs for a spatially explicit STSM of buffelgrass in the Santa Catalina Mountains of southern Arizona. Such simulations could have helped to refine the original scenarios of wildlife and buffelgrass spread, been used to test potential management responses, and target monitoring efforts.

We do not mean to suggest that these particular studies should serve as models of scenario planning, SDM, or simulation modeling. The scenario planning process described by Cary et al. (2012) would benefit from the inclusion of a wider range of stakeholders and a more clearly defined process. The work of Frid et al. (2013) could be built upon by including climate change as a factor affecting the future distribution of buffelgrass, and interactions with fire and land-use change within the simulation model. Nonetheless, together, these studies illustrate a starting point for coupling the three analytical tools described.

\section{CONCLUSION}

Scenario planning, simulation modeling, and SDM are capable of accounting for key social and ecological dynamics, while also addressing the uncertainties inherent in crafting natural resource management plans under climate change. Scenario planning offers a structured and standardized framework for developing scenarios by working across diverse groups and institutions. Simulation models can reproduce complex system dynamics (e.g., feedbacks, emergence, thresholds) associated with these scenarios, and thereby can allow researchers and stakeholders to identify unexpected outcomes of climate change planning. Identifying surprising findings early on in the planning process can help resource managers to avoid, or at least plan for, some of these unintended consequences and more effectively allocate limited resources. Species distribution models can enhance simulation models through rigorous analysis of the relationships between climate, biophysical conditions, and species' ranges.

Despite methodological advancements in each of these areas, there is a gap between the production and use of climate information, and an associated need to shift climate information from useful to usable (Lemos et al. 2012). This shift can be facilitated by emphasizing interaction with stakeholders, providing added value to climate data, and offering opportunities for customization (Lemos et al. 2012). We have attempted to address each of these 
ideals through the above analytical framework. Stakeholder interaction is central to the scenario planning process, which adds value to climate data by identifying key social and biophysical features that should be evaluated through simulation experiments. Value adding is also achieved by linking climate data to the future distributions of species of management interest. These data can be customized to user needs, as identified in the scenario planning process.

Implementing this analytical framework and achieving the goal of producing actionable climate science requires the participation of multiple parties. There is a need for careful coordination between scientists from numerous fields, resource managers, and other stakeholders and community members (e.g., resource users, local experts, indigenous groups). Organizations such as the Department of the Interior's Climate Science Centers, the National Oceanic and Atmospheric Administration's Regional Integrated Science and Assessments (NOAA RISAs; e.g., Western Water Assessment), and the U.S. Department of Agriculture's Regional Climate Hubs are well-placed to implement this strategy for translating and communicating climate information to users and to tailor this information to the needs of different user groups (i.e., retailing).

In sum, species distribution modeling, scenario planning, and simulation modeling are complementary tools for refining conceptualizations of social-ecological systems, engaging a range of stakeholders, combining multiple data types (i.e., social, ecological, and climate), and exploring the effectiveness of climate change adaptation strategies under various future scenarios. It is our hope that the analytical framework presented will catalyze the integration of these and other research tools and the production of actionable information for climate change planning.

Responses to this article can be read online at: http://www.ecologyandsociety.org/issues/responses. $\mathrm{php} / 6813$

\section{Acknowledgments:}

We are grateful to William Travis, Robin O'Malley, and several anonymous reviewers for their comments on previous drafts of this manuscript. This research was funded by the U.S. Geological Survey's North Central Climate Science Center. Any use of trade, product, or firm names is for descriptive purposes only and does not imply endorsement by the U.S. Government.

\section{LITERATURE CITED}

Abel, T., and J. R. Stepp. 2003. A new ecosystems ecology for anthropology. Conservation Ecology 7(3):12. [online] URL: http:// www.consecol.org/vol7/iss 3/art12/

Advisory Committee on Climate Change and Natural Resource Science (ACCCNRS). 2013. Summary report for ACCCNRS meeting 1 (Sept 2013). [online] URL: https://nccwsc.usgs.gov/ $\underline{\text { accenrs }}$

Anselme, B., F. Bousquet, A. Lyet, M. Etienne, B. Fady, and C. Le Page. 2010. Modelling of spatial dynamics and biodiversity conservation on Lure mountain (France). Environmental Modelling and Software 25(11):1385-1398. http://dx.doi. org/10.1016/j.envsoft.2009.09.001

Araújo, M. B., and M. New. 2007. Ensemble forecasting of species distributions. Trends in Ecology and Evolution 22(1):42-47. http:// dx.doi.org/10.1016/j.tree.2006.09.010

Araújo, M. B., and A. T. Peterson. 2012. Uses and misuses of bioclimatic envelope modeling. Ecology 93(7):1527-1539. http:// dx.doi.org/10.1890/11-1930.1

Asrar, G. R., J. W. Hurrell, and A. J. Busalacchi. 2013. A need for 'actionable' climate science and information: summary of WCRP Open Science Conference. Bulletin of the American Meteorological Society 94:ES8-ES12. http://dx.doi.org/10.1175/ BAMS-D-12-00011.1

Aurbacher, J., P. S. Parker, G. A. C. Sanchez, J. Steinbach, E. Reinmuth, J. Ingwersen, and S. Dabbert. 2013. Influence of climate change on short term management of field crops - a modelling approach. Agricultural Systems 119:44-57. http://dx. doi.org/10.1016/j.agsy.2013.04.005

Axelrod, R. 1997. The complexity of cooperation: agent-based models of competition and collaboration. Princeton University Press, Princeton, New Jersey, USA.

Balzter, H., P. W. Braun, and W. Köhler. 1998. Cellular automata models for vegetation dynamics. Ecological Modelling 107 (2-3):113-125. http://dx.doi.org/10.1016/S0304-3800(97)00202-0

Bennett, E. M., S. R. Carpenter, G. D. Peterson, G. S. Cumming, M. Zurek, and P. Pingali. 2003. Why global scenarios need ecology. Frontiers in Ecology and the Environment 1(6):322-329. http://dx.doi.org/10.1890/1540-9295(2003)001[0322:WGSNE]2.0. $\mathrm{CO} ; 2$

Berk, R. 2008. How you can tell if the simulations in computational criminology are any good. Journal of Experimental Criminology 4(3):289-308. http://dx.doi.org/10.1007/ s11292-008-9053-5

Berry, B. J., L. D. Kiel, and E. Elliott. 2002. Adaptive agents, intelligence, and emergent human organization: capturing complexity through agent-based modeling. Proceedings of the National Academy of Sciences 99(Suppl 3):7187-7188. http://dx. doi.org/10.1073/pnas.092078899

Bestelmeyer, B. T., J. R. Brown, K. M. Havstad, R. Alexander, G. Chavez, and J. E. Herrick. 2003. Development and use of stateand-transition models for rangelands. Journal of Range Management 56(2):114-126. http://dx.doi.org/10.2307/4003894

Bestelmeyer, B. T., D. P. Goolsby, and S. R. Archer. 2011. Spatial perspectives in state-and-transition models: a missing link to land management? Journal of Applied Ecology 48(3):746-757. http:// dx.doi.org/10.1111/j.1365-2664.2011.01982.x

Boone, R. B., M. B. Coughenour, K. A. Galvin, and J. E. Ellis. 2002. Addressing management questions for Ngorongoro Conservation Area, Tanzania, using the SAVANNA modelling system. African Journal of Ecology 40:138-150. http://dx.doi. org/10.1046/j.1365-2028.2002.00357.x

Boone, R. B., K. A. Galvin, P. K. Thornton, D. M. Swift, and M. B. Coughenour. 2006. Cultivation and conservation in 
Ngorongoro Conservation Area, Tanzania. Human Ecology 34 (6):809-828. http://dx.doi.org/10.1007/s10745-006-9031-3

Bousquet, F., J.-C. Castella, G. Trébuil, C. Barnaud, S. Boissau, and S. P. Kam. 2007. Using multi-agent systems in a companion modelling approach for agroecosystem management in Southeast Asia. Outlook on Agriculture 36(1):57-62. http://dx.doi. org/10.5367/000000007780223650

Bruch, E., and J. Atwell. 2013. Agent-based models in empirical social research. Sociological Methods and Research October 24, 2013:1-36. http://dx.doi.org/10.1177/0049124113506405

Carpenter, S. R. 2003. Regime shifts in lake ecosystems. Ecology Institute, Oldendorf/Luhe, Germany.

Carpenter, S. R., F. Westley, and M. G. Turner. 2005. Surrogates for resilience of social-ecological systems. Ecosystems 8 (8):941-944. http://dx.doi.org/10.1007/s10021-005-0170-y

Carvalho, S. B., J. C. Brito, E. G. Crespo, M. E. Watts, and H. P. Possingham. 2011. Conservation planning under climate change: toward accounting for uncertainty in predicted species distributions to increase confidence in conservation investments in space and time. Biological Conservation 144(7):2020-2030. http://dx.doi.org/10.1016/j.biocon.2011.04.024

Cary, G. J., E. Collett, M. A. Gill, H. Clayton, and S. Dovers. 2012. Future scenarios for Australian bushfires: report on a bushfire CRC workshop. Australian Journal of Emergency Management 27(3):34-40.

Cobb, A. N., and J. L. Thompson. 2012. Climate change scenario planning: a model for the integration of science and management in environmental decision-making. Environmental Modelling and Software 38:296-305. http://dx.doi.org/10.1016/j.envsoft.2012.06.012

Cooley, P., and E. Solano. 2011. Agent-based model (ABM) validation considerations. Pages 126-131 in SIMUL2011, the third international conference on advances in system simulation, October 23-28, Barcelona, Spain.

Costanza, J. K., J. Hulcr, F. H. Koch, T. Earnhardt, A. J. McKerrow, R. R. Dunn, and J. A. Collazo. 2012. Simulating the effects of the southern pine beetle on regional dynamics 60 years into the future. Ecological Modelling 244:93-103. http://dx.doi. org/10.1016/j.ecolmodel.2012.06.037

Cumming, G. S., G. Barnes, S. Perz, M. Schmink, K. E. Sieving, J. Southworth, M. Binford, R. D. Holt, C. Stickler, and T. Van Holt. 2005. An exploratory framework for the empirical measurement of resilience. Ecosystems 8(8):975-987. http://dx. doi.org/10.1007/s10021-005-0129-Z

DeAngelis, D. L., and W. M. Mooij. 2005. Individual-based modeling of ecological and evolutionary processes. Annual Review of Ecology, Evolution, and Systematics 36(1):147-168. http://dx.doi.org/10.1146/annurev.ecolsys.36.102003.152644

Döll, P. 2004. Qualitative-quantitative scenarios as a means to support sustainability-oriented regional planning. Pages 47-60 in

A. Marquina, editor. Environmental challenges in the Mediterranean 2000-2050. NATO Science Series, Springer, Amsterdam, Netherlands. http://dx.doi.org/10.1007/978-94-007-0973-7 3

Dowsley, M., R. H. Lemelin, and Washaho First Nation at Fort Severn. 2013. Developing community capacities through scenario planning for natural resource management: a case study of polar bears. Society and Natural Resources 26(8):977-986. http://dx. doi. org/10.1080/08941920.2012.724522

Elith, J., and J. Franklin. 2013. Species distribution modelling. Pages 692-705 in S. A. Levin, editor. Encyclopedia of biodiversity. Academic, Waltham, Massachusetts, USA. http://dx.doi. org/10.1016/B978-0-12-384719-5.00318-X

Epstein, J. M., and R. L. Axtell. 1996. Growing artificial societies: social science from the bottom up. MIT Press, Cambridge, Massachusetts, USA.

Erlien, C. M., J. P. Tuttle, A. L. McCleary, C. F. Mena, and S. J. Walsh. 2006. Complexity theory and spatial simulations of land use/land cover dynamics: the use of 'what if' scenarios for education, land management, and decision-making. Geocarto International 21(4):67-74. http://dx.doi.org/0.1080/10106040608542404

Evers, L. B., R. F. Miller, P. S. Doescher, M. Hemstrom, and R. P. Neilson. 2013. Simulating current successional trajectories in sagebrush ecosystems with multiple disturbances using a stateand-transition modeling framework. Rangeland Ecology and Management 66(3):313-329. http://dx.doi.org/10.2111/REMD-11-00220.1

Flaxman, M., and J. C. Vargas-Moreno. 2011. Considering climate change in state wildlife action planning: a spatial resilience planning approach. Report No. FWC-2011. Department of Urban Studies and Planning, Massachusetts Institute of Technology, Cambridge, Massachusetts, USA.

Foran, T., J. Ward, E. J. Kemp-Benedict, and A. Smajgl. 2013. Developing detailed foresight narratives: a participatory technique from the Mekong region. Ecology and Society 18(4): 6. http://dx.doi.org/10.5751/ES-05796-180406

Forbis, T. A., L. Provencher, L. Frid, and G. Medlyn. 2006. Great Basin land management planning using ecological modeling. Environmental Management 38(1):62-83. http://dx.doi.org/10.1007/ $\underline{\mathrm{s} 00267-005-0089-2}$

Franklin, J. 2013. Species distribution models in conservation biogeography: developments and challenges. Diversity and Distributions 19(10):1217-1223. http://dx.doi.org/10.1111/ddi.12125

Frid, L., T. Holcombe, J. T. Morisette, A. D. Olsson, L. Brigham, T. M. Bean, J. L. Betancourt, and K. Bryan. 2013. Using stateand-transition modeling to account for imperfect detection in invasive species management. Invasive Plant Science and Management 6(1):36-47. http://dx.doi.org/10.1614/IPSM-D-11-00065.1

Frid, L., and J. F. Wilmshurst. 2009. Decision analysis to evaluate control strategies for crested wheatgrass (Agropyron cristatum) in Grasslands National Park of Canada. Invasive Plant Science and Management 2(4):324-336. http://dx.doi.org/10.1614/IPSM-09-006.1

Grimm, V., E. Revilla, U. Berger, F. Jeltsch, W. M. Mooij, S. F. Railsback, H.-H. Thulke, J. Weiner, T. Wiegand, and D. L. DeAngelis. 2005. Pattern-oriented modeling of agent-based complex systems: lessons from ecology. Science 310 (5750):987-991. http://dx.doi.org/10.1126/science.1116681

Guisan, A., and W. Thuiller. 2005. Predicting species distribution: offering more than simple habitat models. Ecology Letters 8 (9):993-1009. http://dx.doi.org/10.1111/j.1461-0248.2005.00792. $\underline{x}$ 
Guisan, A., and N. E. Zimmermann. 2000. Predictive habitat distribution models in ecology. Ecological Modelling 135 (2-3):147-186. http://dx.doi.org/10.1016/S0304-3800(00)00354-9

Gurung, T. R., F. Bousquet, and G. Trébuil. 2006. Companion modeling, conflict resolution, and institution building: sharing irrigation water in the Lingmuteychu Watershed, Bhutan. Ecology and Society 11(2): 36. [online] URL: http://www. ecologyandsociety.org/vol11/iss2/art36/

Halofsky, J. E., M. A. Hemstrom, D. R. Conklin, J. S. Halofsky, B. K. Kerns, and D. Bachelet. 2013. Assessing potential climate change effects on vegetation using a linked model approach. Ecological Modelling 266:131-143. http://dx.doi.org/10.1016/j. ecolmodel.2013.07.003

Hassani-Mahmooei, B., and B. W. Parris. 2012. Climate change and internal migration patterns in Bangladesh: an agent-based model. Environment and Development Economics 17:763-780. http://dx.doi.org/10.1017/S1355770X12000290

Heikkinen, R. K., M. Luoto, M. B. Araúo, R. Virkkala, W. Thuiller, and M. T. Sykes. 2006. Methods and uncertainties in bioclimatic envelope modelling under climate change. Progress in Physical Geography 30(6):751-777. http://dx.doi. org/10.1177/0309133306071957

Holland, J. H. 1995. Hidden order: how adaptation builds complexity. Perseus, New York, New York, USA.

Janssen, M., and B. de Vries. 1998. The battle of perspectives: a multi-agent model with adaptive responses to climate change. Ecological Economics 26(1):43-65. http://dx.doi.org/10.1016/ $\underline{\text { S0921-8009(97)00062-1 }}$

Kahane, A. 1998. Learning from Mont Fleur: scenarios as a tool for discovering common ground. Deeper News 7(1):1-4.

Kass, G. S., R. F. Shaw, T. Tew, and D. W. Macdonald. 2011. Securing the future of the natural environment: using scenarios to anticipate challenges to biodiversity, landscapes and public engagement with nature. Journal of Applied Ecology 48 (6):1518-1526. http://dx.doi.org/10.1111/j.1365-2664.2011.02055. $\underline{x}$

Keane, R. E., L. M. Holsinger, R. A. Parsons, and K. Gray. 2008. Climate change effects on historical range and variability of two large landscapes in western Montana, USA. Forest Ecology and Management 254(3):375-389. http://dx.doi.org/10.1016/j.

foreco.2007.08.013

Kemp-Benedict, E. 2004. From narrative to number: a role for quantitative models in scenario analysis. Pages 765-770 in C. PahlWostl, S. Schmidt, A. E. Rizzoli, and A. J. Jakeman, editors. Complexity and integrated resources management, Transactions of the 2nd biennial meeting of the International Environmental Modelling and Software Society, IEMSs, Manno, Switzerland.

Knapp, C. N., M. E. Fernandez-Gimenez, D. D. Briske, B. T. Bestelmeyer, and X. B. Wu. 2011. An assessment of state-andtransition models: perceptions following two decades of development and implementation. Rangeland Ecology and Management 64(6):598-606. http://dx.doi.org/10.2111/REMD-10-00188.1

Kniveton, D., C. Smith, and S. Wood. 2011. Agent-based model simulations of future changes in migration flows for Burkina
Faso. Global Environmental Change 21:S34-S40. http://dx.doi. org/10.1016/j.gloenvcha.2011.09.006

Kok, K., and H. van Delden. 2009. Combining two approaches of integrated scenario development to combat desertification in the Guadalentin watershed, Spain. Environment and Planning B: Planning and Design 36(1):49-66. http://dx.doi.org/10.1068/ $\underline{\text { b32137 }}$

Kujala, H., A. Moilanen, M. B. Araújo, and M. Cabeza. 2013. Conservation planning with uncertain climate change projections. PLOS ONE 8(2):e53315. http://dx.doi.org/10.1371/ journal.pone.0053315

Lemos, M. C., C. J. Kirchhoff, and V. Ramprasad. 2012. Narrowing the climate information usability gap. Nature Climate Change 2(11):789-794. http://dx.doi.org/10.1038/nclimate1614

Levin, S. A. 1998. Ecosystems and the biosphere as complex adaptive systems. Ecosystems 1(5):431-436. http://dx.doi. org/10.1007/s100219900037

Li, H., and J. F. Reynolds. 1997. Modeling effects of spatial pattern, drought, and grazing on rates of rangeland degradation: a combined Markov and cellular automaton approach. Pages 211-230 in D. A. Quattrochi and M. F. Goodchild, editors. Scale in remote sensing and GIS. Lewis, Boca Raton, Florida, USA.

Mahmoud, M., Y. Liu, H. Hartmann, S. Stewart, T. Wagener, D. Semmens, R. Stewart, H. Gupta, D. Dominguez, F. Dominguez, D. Hulse, R. Letcher, B. Rashleigh, C. Smith, R. Street, J. Ticehurst, M. Twery, H. van Delden, R. Waldick, D. White, and L. Winter. 2009. A formal framework for scenario development in support of environmental decision-making. Environmental Modelling and Software 24(7):798-808. http://dx.doi.org/10.1016/ j.envsoft.2008.11.010

Malanson, G. P., Y. Zeng, and S. J. Walsh. 2006. Complexity at advancing ecotones and frontiers. Environment and Planning A 38 (4):619-632. http://dx.doi.org/10.1068/a37340

Manson, S. M. 2001. Simplifying complexity: a review of complexity theory. Geoforum 32(3):405-414. http://dx.doi. org/10.1016/S0016-7185(00)00035-X

Matthews, R. B., N. G. Gilbert, A. Roach, J. G. Polhill, and N. M. Gotts. 2007. Agent-based land-use models: a review of applications. Landscape Ecology 22:1447-1459. http://dx.doi. org/10.1007/s10980-007-9135-1

Miller, B. W., I. Breckheimer, A. L. McCleary, L. GuzmánRamirez, S. C. Caplow, J. C. Jones-Smith, and S. J. Walsh. 2010 Using stylized agent-based models for population-environment research: a case study from the Galápagos Islands. Population and Environment 31(6):401-426. http://dx.doi.org/10.1007/s11111-010-0110-4

Miller, B. W., P. W. Leslie, and J. T. McCabe. 2014. Coping with natural hazards in a conservation context: resource-use decisions of Maasai households during recent and historical drought. Human Ecology, in press. http://dx.doi.org/10.1007/s10745-014-9683-3

Millington, J., R. Romero-Calcerrada, J. Wainwright, and G. Perry. 2008. An agent-based model of Mediterranean agricultural land-use/cover change for examining wildfire risk. Journal of Artificial Societies and Social Simulation 11(4):4. [online] URL: http://jasss.soc.surrey.ac.uk/11/4/4.html 
Millington, J. D. A., J. Wainwright, G. L. W. Perry, R. RomeroCalcerrada, and B. D. Malamud. 2009. Modelling Mediterranean landscape succession-disturbance dynamics: a landscape firesuccession model. Environmental Modelling and Software 24 (10):1196-1208. http://dx.doi.org/10.1016/j.envsoft.2009.03.013

Morisette, J. T., C. S. Jarnevich, T. R. Holcombe, C. B. Talbert, D. Ignizio, M. K. Talbert, C. Silva, D. Koop, A. Swanson, and N. E. Young. 2013. VisTrails SAHM: visualization and workflow management for species habitat modeling. Ecography 36 (2):129-135. http://dx.doi.org/10.1111/j.1600-0587.2012.07815.x

Nix, H. 1986. A biogeographic analysis of Australian elapid snakes. Pages 4-15 in R. Longmore, editor. Atlas of elapid snakes in Australia. Australian Flora and Fauna Series, Australian Government Publishing Service, Canberra, Australia.

Parker, D. C., S. M. Manson, M. A. Janssen, M. J. Hoffmann, and P. Deadman. 2003. Multi-agent systems for the simulation of land-use and land-cover change: a review. Annals of the Association of American Geographers 93(2):314-337. http://dx. doi.org/10.1111/1467-8306.9302004

Patt, A., and B. Siebenhüner. 2005. Agent-based modeling and adaptation to climate change. Vierteljahrshefte zur Wirtschaftsforschung 74(2):310-320. http://dx.doi.org/10.3790/vjh.74.2.310

Peterson, G. D. 2007. Using scenario planning to enable an adaptive co-management process in the Northern Highlands Lake District of Wisconsin. Pages 286-307 in D. Armitage, F. Berkes, and N. Doubleday, editors. Adaptive co-management: collaboration, learning, and multi-level governance. UBC Press, Vancouver, British Columbia, Canada.

Peterson, G. D., T. D. Beard, Jr., B. E. Beisner, E. M. Bennett, S. R. Carpenter, G. Cumming, C. L. Dent, and T. D. Havlicek. $2003 b$. Assessing future ecosystem services: a case study of the Northern Highlands Lake District, Wisconsin. Ecology and Society 7(3): 1. [online] URL: http://www.consecol.org/vol7/iss3/art1/

Peterson, G. D., G. S. Cumming, and S. R. Carpenter. $2003 a$. Scenario planning: a tool for conservation in an uncertain world. Conservation Biology 17(2):358-366. http://dx.doi.org/10.1046/ j.1523-1739.2003.01491.x

Portugali, J. 2006. Complexity theory as a link between space and place. Environment and Planning A 38(4):647-664. http://dx.doi. org/10.1068/a37260

Provencher, L., T. A. Forbis, L. Frid, and G. Medlyn. 2007. Comparing alternative management strategies of fire, grazing, and weed control using spatial modeling. Ecological Modelling 209(2-4):249-263. http://dx.doi.org/10.1016/j.ecolmodel.2007.06.030

Rinaudo, J.-D., L. Maton, I. Terrason, S. Chazot, A. RichardFerroudji, and Y. Caballero. 2013. Combining scenario workshops with modeling to assess future irrigation water demands. Agricultural Water Management 130:103-112. http:// dx.doi.org/10.1016/j.agwat.2013.08.016

Rose, M., and J. Star. 2013. Using scenarios to explore climate change: a handbook for practitioners. National Park Service, U.S. Department of the Interior, Washington, D.C., USA. [online] URL: http://climate.calcommons.org/bib/using-scenarios-exploreclimate-change-handbook-practitioners
Rotmans, J., M. van Asselt, C. Anastasi, S. Greeuw, J. Mellors, S. Peters, D. Rothman, and N. Rijkens. 2000. Visions for a sustainable Europe. Futures 32(9-10):809-831. http://dx.doi. org/10.1016/S0016-3287(00)00033-1

Schelling, T. C. 1971. Dynamic models of segregation. Journal of Mathematical Sociology 1(2):143-186. http://dx.doi. org/10.1080/0022250X.1971.9989794

Schlüter, M., H. Leslie, and S. Levin. 2009. Managing water-use trade-offs in a semi-arid river delta to sustain multiple ecosystem services: a modeling approach. Ecological Research 24 (3):491-503. http://dx.doi.org/10.1007/s11284-008-0576-z

Schlüter, M., and C. Pahl-Wostl. 2007. Mechanisms of resilience in common-pool resource management systems: an agent-based model of water use in a river basin. Ecology and Society 12(2): 4. [online] URL: http://www.ecologyandsociety.org/vol12/iss2/art4/

Schoemaker, P. J. H. 1995. Scenario planning: a tool for strategic thinking. Sloan Management Review 36:25-40. [online] URL: http://sloanreview.mit.edu/article/scenario-planning-a-tool-for-strategicthinking/

Schouten, M., P. Opdam, N. Polman, and E. Westerhof. 2013. Resilience-based governance in rural landscapes: experiments with agri-environment schemes using a spatially explicit agentbased model. Land Use Policy 30(1):934-943. http://dx.doi. org/10.1016/j.landusepol.2012.06.008

Sinclair, S. J., M. D. White, and G. R. Newell. 2010. How useful are species distribution models for managing biodiversity under future climates? Ecology and Society 15(1): 8. [online] URL: http:// www.ecologyandsociety.org/vol15/iss 1/art8/

Smajgl, A. 2010. Challenging beliefs through multi-level participatory modelling in Indonesia. Environmental Modelling and Software 25(11):1470-1476. http://dx.doi.org/10.1016/j. envsoft.2010.04.008

Smajgl, A., and J. Ward. 2013. The water-food-energy nexus in the Mekong Region: assessing development strategies considering cross-sectoral and transboundary impacts. Springer, Amsterdam, Netherlands.

Smith, C., D. Kniveton, R. Black, and S. Wood. 2008. Predictive modelling. Forced Migration Review 31:58-59.

Snover, A. K., N. J. Mantua, J. S. Littell, M. A. Alexander, M. M. McClure, and J. Nye. 2013. Choosing and using climate-change scenarios for ecological-impact assessments and conservation decisions. Conservation Biology 27(6):1147-1157. http://dx.doi. org/10.1111/cobi.12163

Staudt, A., A. K. Leidner, J. Howard, K. A. Brauman, J. S. Dukes, L. J. Hansen, C. Paukert, J. Sabo, and L. A. Solórzano. 2013. The added complications of climate change: understanding and managing biodiversity and ecosystems. Frontiers in Ecology and the Environment 11(9):494-501. http://dx.doi.org/10.1890/120275

Strand, E. K., L. A. Vierling, S. C. Bunting, and P. E. Gessler. 2009. Quantifying successional rates in western aspen woodlands: current conditions, future predictions. Forest Ecology and Management 257(8):1705-1715. http://dx.doi.org/10.1016/j. foreco.2009.01.026 
Stringham, T. K., W. C. Krueger, and P. L. Shaver. 2001. Special Report Number 1024: States, transitions, and thresholds: further refinement for rangeland applications. Oregon State University Agricultural Experiment Station, Corvallis, Oregon, USA.

Talbert, C., M. Talbert, J. Morisette, and D. Koop. 2013. Data management challenges in species distribution modeling. IEEE Data Engineering Bulletin 36(4):31-40. [online] URL: http://sites. computer.org/debull/A13dec/p31.pdf

Thuiller, W. 2007. Biodiversity: climate change and the ecologist. Nature 448(7153):550-552. http://dx.doi.org/10.1038/448550a

Tompkins, E. L., R. Few, and K. Brown. 2008. Scenario-based stakeholder engagement: incorporating stakeholders preferences into coastal planning for climate change. Journal of Environmental Management 88(4):1580-1592. http://dx.doi.org/10.1016/j. jenvman.2007.07.025

Vargas-Moreno, J. C., and M. Flaxman. 2012. Using participatory scenario simulation to plan for conservation under climate change in the greater everglades landscape. Pages 27-56 in H. A. Karl, L. Scarlett, J. C. Vargas-Moreno, and M. Flaxman, editors. Restoring lands - coordinating science, politics and action: complexities of climate and governance. Springer, Amsterdam, Netherlands. http://dx.doi.org/10.1007/978-94-007-2549-2_3

Veloz, S. D., N. Nur, L. Salas, D. Jongsomjit, J. Wood, D. Stralberg, and G. Ballard. 2013. Modeling climate change impacts on tidal marsh birds: restoration and conservation planning in the face of uncertainty. Ecosphere 4(4):art49. http://dx.doi. org/10.1890/ES12-00341.1

Voinov, A., and F. Bousquet. 2010. Modelling with stakeholders. Environmental Modelling and Software 25(11):1268-1281. http:// dx.doi.org/10.1016/i.envsoft.2010.03.007

Wack, P. 1985. Scenarios: uncharted waters ahead. Harvard Business Review 63:72-89. [online] URL: http://hbr.org/1985/09/ scenarios-uncharted-waters-ahead

Walker, B., and D. Salt. 2006. Resilience thinking: sustaining ecosystems and people in a changing world. Island, Washington, D.C., USA.

Walker, W. E., P. Harremoës, J. Rotmans, J. P. van der Sluijs, M. B. A. van Asselt, P. Janssen, and M. P. Krayer von Krauss. 2003. Defining uncertainty: a conceptual basis for uncertainty management in model-based decision support. Integrated Assessment 4(1):5-17. http://dx.doi.org/10.1076/iaij.4.1.5.16466

Walsh, S. J., B. Entwisle, R. R. Rindfuss, and P. H. Page. 2006. Spatial simulation modelling of land use/land cover change scenarios in northeastern Thailand: a cellular automata approach. Journal of Land Use Science 1(1):5-28. http://dx.doi. org/10.1080/17474230600604213

Walsh, S. J., G. P. Malanson, B. Entwisle, R. R. Rindfuss, P. J. Mucha, B. W. Heumann, P. M. McDaniel, B. G. Frizzelle, A. M. Verdery, N. E. Williams, X. Yao, and D. Ding. 2013. Design of an agent-based model to examine population-environment interactions in Nang Rong District, Thailand. Applied Geography 39:183-198. http://dx.doi.org/10.1016/j.apgeog.2012.12.010

Walz, A., C. Lardelli, H. Behrendt, A. Grêt-Regamey, C. Lundström, S. Kytzia, and P. Bebi. 2007. Participatory scenario analysis for integrated regional modeling. Landscape and Urban Planning 81(1-2):114-131. http://dx.doi.org/10.1016/j. landurbplan.2006.11.001

Wang, J., D. G. Brown, R. L. Riolo, S. E. Page, and A. Agrawal. 2013. Exploratory analyses of local institutions for climate change adaptation in the Mongolian grasslands: an agent-based modeling approach. Global Environmental Change 23 (5):1266-1276. http://dx.doi.org/10.1016/j.gloenvcha.2013.07.017

Wang, T., E. M. Campbell, G. A. O’Neill, and S. N. Aitken. 2012. Projecting future distributions of ecosystem climate niches: uncertainties and management applications. Forest Ecology and Management 279:128-140. http://dx.doi.org/10.1016/j.foreco.2012.05.034

Weeks, D., P. Malone, and L. Welling. 2011. Climate change scenario planning: a tool for managing parks into uncertain futures. Park Science 28(1):26-33. [online] URL: http://www. nature.nps.gov/parkscience/index.cfm?ArticleID $=475$

Westhoek, H. J., M. van den Berg, and J. A. Bakkes. 2006. Scenario development to explore the future of Europe's rural areas. Agriculture, Ecosystems and Environment 114(1):7-20. http://dx. doi.org/10.1016/j.agee.2005.11.005

Westoby, M., B. Walker, and I. Noy-Meir. 1989. Opportunistic management for rangelands not at equilibrium. Journal of Range Management 42(4):266-274. http://dx.doi.org/10.2307/3899492

Yan, D., U. A. Schneider, E. Schmid, H. Q. Huang, L. Pan, and O. Dilly. 2013. Interactions between land use change, regional development, and climate change in the Poyang Lake district from 1985 to 2035. Agricultural Systems 119:10-21. http://dx.doi. org/10.1016/j.agsy.2013.04.001

Zhang, T., J. Zhan, J. Huang, R. Yu, and C. Shi. 2013. An agentbased reasoning of impacts of regional climate changes on land use changes in the three-river headwaters region of China. Advances in Meteorology 2013:1-9. http://dx.doi.org/10.1155/2013/248194

Ziervogel, G., M. Bithell, R. Washington, and T. Downing. 2005. Agent-based social simulation: a method for assessing the impact of seasonal climate forecast applications among smallholder farmers. Agricultural Systems 83(1):1-26. http://dx.doi. org/10.1016/j.agsy.2004.02.009 